\title{
Postural Reorganization Induced by Torso Cutaneous Covibration
}

\author{
Beom-Chan Lee, ${ }^{1}$ Bernard J. Martin, ${ }^{2}$ Allison Ho, ${ }^{1}$ and Kathleen H. Sienko ${ }^{1,3}$ \\ Departments of ${ }^{1}$ Mechanical Engineering, ${ }^{2}$ Industrial \& Operations Engineering, and ${ }^{3}$ Biomedical Engineering, University of Michigan, Ann Arbor, \\ Michigan 48109
}

Cutaneous information from joints has been attributed proprioceptive properties similar to those of muscle spindles. This study aimed to assess whether vibration-induced changes in torso cutaneous information contribute to whole-body postural reorganization in humans. Ten healthy young adults stood in normal and Romberg stances with six vibrating actuators positioned on the torso in contact with the skin over the left and right external oblique, internal oblique, and erector spinae muscle locations at the L4/L5 vertebrae level. Vibrations around the torso were randomly applied at two locations simultaneously (covibration) or at all locations simultaneously. Kinematic analysis of the body segments indicated that covibration applied to the skin over the internal oblique muscles induced shifts of both the head and torso in the anterior direction (torso flexion) while the hips shifted in the posterior direction (ankle plantar flexion). Conversely, covibration applied to the skin over the erector spinae muscle locations produced opposite effects. However, covibration applied to the skin over the left internal oblique and left erector spinae, the right internal oblique and right erector spinae, or at all locations simultaneously did not induce any significant postural changes. In addition, the center of pressure position as measured by the force plate was unaffected by all covibration conditions tested. These results were independent of stance and suggest an integrated and coordinated reorganization of posture in response to vibration-induced changes in cutaneous information. In addition, combinations of vibrotactile stimuli over multiple locations exhibit directional summation properties in contrast to the individual responses we observed in our previous work.

\section{Introduction}

Upright stance, which requires the stabilization of a multisegmental linkage system, is maintained by feedback (involving the integration of sensory inputs from visual, vestibular, cutaneous, and muscle proprioceptive systems) and/or feedforward mechanisms (Haas et al., 1989; Massion, 1992) and may be achieved by using various combinations/coordination of ankle (Gatev et al., 1999), hip (Horak and Kuo, 2000), and head (Kim et al., 2000; Honegger et al., 2012) movements. Both in-phase and antiphase modes have been observed between upper and lower body segments during quiet stance (Creath et al., 2005; Kiemel et al., 2008).

The upright standing posture may be modified in response to multiple influences, including, for example, self-initiated movement (Crenna et al., 1987), microgravity (Roll et al., 1998), and altered perception of self-motion (Anderson et al., 1986). Postural modifications in response to such stimuli are frequently characterized by either center of pressure (COP) or body kine-

Received Oct. 4, 2012; revised March 15, 2013; accepted March 20, 2013.

Author contributions: B.-C.L., B.J.M., and K.H.S. designed research; B.-C.L., B.J.M., A.H., and K.H.S. performed research; B.-C.L., B.J.M., and K.H.S. analyzed data; B.-C.L., B.J.M., and K.H.S. wrote the paper.

This work was supported by the National Science Foundation's CAREER program (funded under the American Recovery and Reinvestment Act of 2009) Grant RAPD-0846471 to K.H.S. We thank the Center for Statistical Consultation and Research at the University of Michigan for consultation regarding statistical analysis.

The authors declare no competing financial interests.

Correspondence should be addressed to Dr. Kathleen H. Sienko, 3116 George G. Brown Laboratory, 2350 Hayward Street, Ann Arbor, MI 48109-2125. E-mail: sienko@umich.edu.

DOI:10.1523/JNEUROSCI.4715-12.2013

Copyright $\odot 2013$ the authors $\quad 0270-6474 / 13 / 337870-07 \$ 15.00 / 0$ matic data; the use of only one dataset excludes the possibility of a more comprehensive examination of the postural reorganization strategy used by the CNS. Furthermore, the upright standing posture may also be modified by involuntary responses to muscle vibration applied locally to the neck (Ivanenko et al., 1999; Kavounoudias et al., 1999), knee (Edin, 2001; Collins et al., 2005), ankle (Goodwin et al., 1972; Kavounoudias et al., 2001), or whole-body segments (Martin et al., 1980). For example, dorsal neck muscle vibration induces an anterior leaning of the body, as indicated by the position of the COP (Kavounoudias et al., 1999) and kinematic measurements (Ivanenko et al., 1999). This effect is interpreted as an automatic corrective response to the CNS assumed posterior leaning of the body based on the evidence that vibration simulates a lengthening of the stimulated muscles (Goodwin et al., 1972). We recently showed that cutaneous vibration applied to the torso skin at the L4/L5 vertebrae level induces corrective directional postural shifts similar to those induced by muscle vibration (i.e., a single vibration applied to the anterior torso skin over the right internal oblique induces torso inclinations in the direction of the applied vibration azimuth) (Lee et al., 2012b). However, with one exception (Thompson et al., 2007), none of these studies simultaneously analyzed the kinematics and kinetics of postural changes to determine the relationship between postural reorganization and COP variations when sensory information is modified by vibration.

Another recent study found that dorsal neck muscle vibration induced a posterior leaning of the head whereas all of the other body segments leaned in the anterior direction (Verrel et al., 2011). Thus, a coordinated multisegmental response to torso cu- 

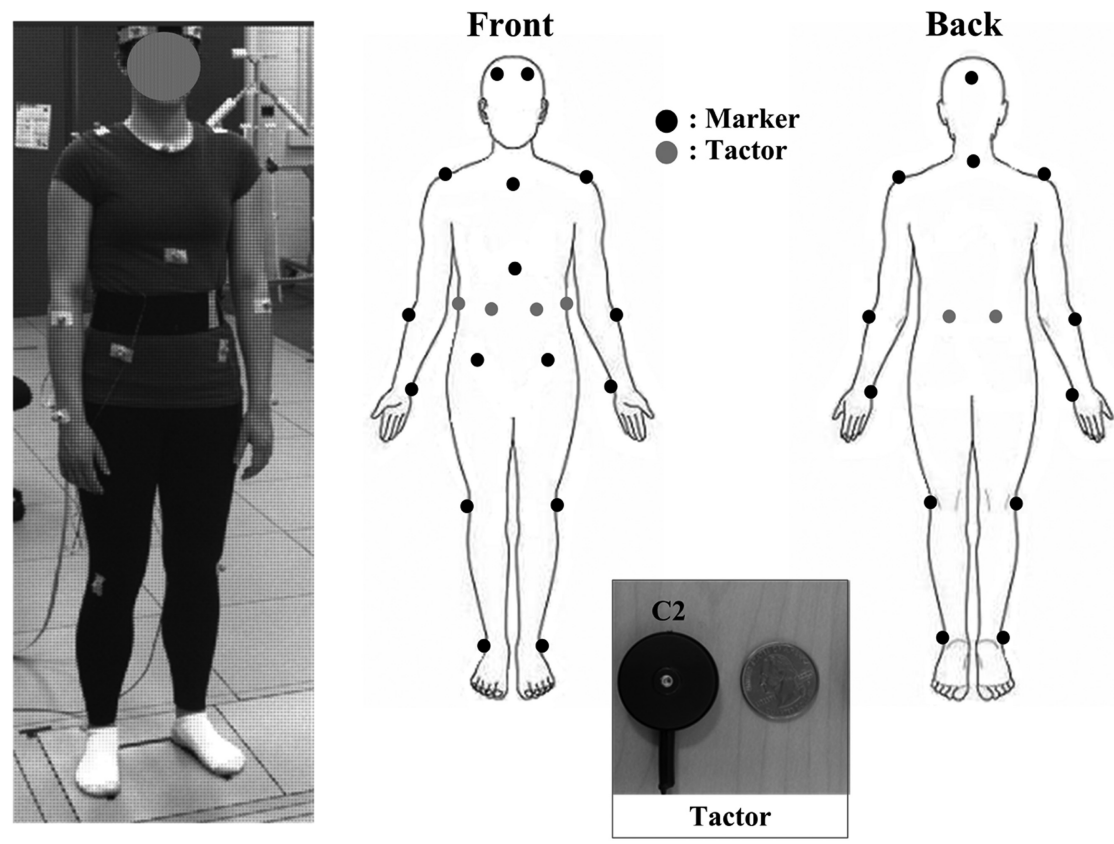

Figure 1. Diagram and digital image of the 18 passive markers and six $C 2$ tactor locations applied to the body and a digital image of a $\mathrm{C} 2$ tactor.

taneous vibration may be likely. Furthermore, it has been found that vibratory stimuli applied simultaneously over two muscle groups on either the neck and/or ankle resulted in a summation of postural responses (Kavounoudias et al., 1999).

Hence, this study tested two hypotheses as follows: (1) if changes in torso posture induced by torso vibrotactile stimulations (Lee et al., 2012b) are accompanied by a multisegmental reorganization of posture, then the COP location should be controlled to maintain balance; and (2) covibration (vibration stimuli applied simultaneously over two skin areas) applied to torso areas has a summation effect on postural responses in the absence of instructions.

\section{Materials and Methods}

Participants. Ten healthy young adults recruited among university students ( 5 males, 5 females; mean age $22.0 \pm 3.1$ years) naive to the purpose of the experiments participated in this study. Exclusion criteria were any neurological or functionally significant musculoskeletal dysfunction, or a body mass index $>30 \mathrm{~kg} / \mathrm{m}^{2}$. Each participant gave informed consent before the start of the experimental procedures, and this study was conducted in accordance with the Helsinki Declaration and approved by the University of Michigan Institutional Review Board.

Instrumentation. A passive motion capture system (Vicon MX) was used to measure the kinematics of body segments. Eighteen markers were placed on the head (frontal and occipital bones), neck (C7), shoulders (acromion), arms (lateral epicondyle of the ulnar and ulnar styloid process), torso (manubrium, xiphoid process, and L5/S1 vertebrae level on anterior superior iliac spine), knees (lateral epicondyle of femur), and ankles (lateral malleolus), as shown in Figure 1. A force platform (OR6-7, Advanced Mechanical Technology) was used to record the COP displacements. Both the marker (accuracy better than $1.0 \mathrm{~mm}$ ) and COP displacements (accuracy $\sim 1.0 \mathrm{~mm}$ ) were simultaneously sampled at a rate of $100 \mathrm{~Hz}$. Vibrotactile stimulations were generated by six linear actuators (C2, Engineering Acoustics), herein referred to as tactors. Consistent with our previous study (Lee et al., 2012b), the tactors were placed on the skin over the areas corresponding to the left and right internal oblique $\left( \pm 30^{\circ}\right)$, external oblique $\left( \pm 90^{\circ}\right)$, and erector spinae $\left( \pm 160^{\circ}\right)$ muscles at approximately the level of the L4/L5 vertebrae (note that numeric values correspond to azimuth angles relative to the sagittal plane $\left[0^{\circ}\right]$ with clockwise-positive increments). The anatomical indications are used to facilitate the labeling of vibration locations in result descriptions but do not imply an association with muscle stimulation. The tactor had a cylindrical moving probe ( $8 \mathrm{~mm}$ diameter) at the center. The measured peak-to-peak displacement amplitude of the vibrating probe was $200 \mu \mathrm{m}$ at the selected stimulation frequency of $250 \mathrm{~Hz}$ for each tactor when tested against a material simulating physiological tissue stiffness (Lee et al., 2012a). All tactors were attached with Velcro to an elastic belt worn around the torso. The stimulation frequency was selected to avoid the response of muscle spindles (Burke et al., 1976a, 1976b; Roll et al., 1989) and to remain within the one-to-one frequency response of fast-adapting cutaneous receptors (Knibestol and Vallbo, 1970; Johansson et al., 1982; Vedel and Roll, 1982; Ribot-Ciscar et al., 1989). In addition, vibration attenuation by soft tissues at the selected frequency (Lundstrom, 1984); unreliable or nearly inexistent driving of muscle spindles by sinusoidal tendon vibration (magnitude $<100 \mu \mathrm{m}$ ) at frequencies $>80 \mathrm{~Hz}$ (Fallon and Macefield, 2007); and similarity of directional effects produced by 50 and $200 \mu \mathrm{m}$ stimulations at $250 \mathrm{~Hz}$ (Lee et al., 2012a) also support the likelihood of negligible activation of muscle spindles. Hence, although a response of muscle stretch receptors cannot be completely excluded without anesthesia, its contribution is assumed to be inconsequential in the present context and our stimulation may be considered as predominantly tactile.

Procedure. For the experimental trials, each participant stood with their eyes closed on a force plate in either a normal or Romberg stance. Normal stance was defined as having the feet hip-width apart with a $15^{\circ}$ lateral rotation angle and a $15 \mathrm{~cm}$ heel-to-heel distance. Romberg stance was defined as feet together. The order of stance condition was randomized. Participants were instructed to stand in an upright posture, keep their knees extended, relax their arms down at their sides, and breathe normally during data collection. Participants were also instructed to fix their gaze on an " $\mathrm{X}$ " placed $\sim 2 \mathrm{~m}$ ahead at eye level before closing their eyes for the duration of the trial to further promote a standard initial posture within and among participants. All participants wore earplugs to eliminate environmental noise and minimize the use of audible cues.

Each trial had a total duration of $15 \mathrm{~s}$ and consisted of three consecutive $5 \mathrm{~s}$ periods with no vibration (pre), vibration (per), and no vibration (post), respectively. Four different covibration conditions were used and labeled as follows: right and left internal oblique (B IO), right and left erector spinae (B ES), right internal oblique and right erector spinae ( $\mathrm{R}$ IO-ES), and left internal oblique and left erector spinae (L IO-ES). Trials were performed using one of the "covibration" conditions (simultaneous vibrotactile stimulations over the skin of two locations) or the "ALL" condition (simultaneous vibrotactile stimulations over the skin of all locations: left and right IO, EO, and ES). Each condition was tested twice in a random order (i.e., a total of 20 trials: 5 vibration conditions $\times 2$ stances $\times 2$ repetitions) and was recorded for each participant. Participants were naive to the selected locations of covibrations.

Data analysis. The processing of recorded signals from both the motion capture system and force plate was performed using MATLAB (MathWorks). The recorded signals (marker and COP displacements) were low-pass filtered with a zero phase, second-order Butterworth filter with a $10 \mathrm{~Hz}$ cutoff frequency because the frequency of body kinematic signals is $<10 \mathrm{~Hz}$ during quiet standing (Winter, 1995; Sienko et al., 2010; Verrel et al., 2011). The two positions of each pair of homonymous markers (which were placed symmetrically on the aforementioned body landmarks) were averaged to generate a postural profile represented in the midsagittal plane. The four metrics used for marker data analysis 
were body segment linear and angular displacement, the SD of angular displacement (herein termed angular dispersion $[\mathrm{AD}]$ ) and the anchoring index (AI) defined below. All metrics were computed for each period (pre-, per-, and post-vibration) in both the anteriorposterior (AP, i.e., sagittal plane) and mediolateral (ML, i.e., frontal plane) directions.

Displacements of markers placed on body landmarks, and joint angles (i.e., neck, torso, knee, and ankle) were used to quantify postural changes. Markers attached to the head (frontal and occipital bones), neck (C7), lower torso (L5/S1 relative to anterior superior iliac spine), knee (lateral epicondyle of femur), and ankle (external malleolus) were used to record the body landmark displacements. Joint angles indicating the orientation of the superior body segment relative to the absolute vertical direction were computed by trigonometric methods using measured marker positions in AP and ML directions. The computed joint angles represent posture configurations before and at the end of the vibration period for each condition. For example, the neck angle was determined by the position of the head relative to the neck joint center of rotation with respect to the absolute vertical direction. Similarly, the torso,

knee, and ankle angles were computed using the neck-L5/S1, L5/S1knee, and knee-ankle segments, respectively (see Fig. $3 A$, representation of the linkage system). For the sake of simplicity, the pelvic segment was not considered as an independent segment because the magnitudes of the vibration-elicited torso movements were small; and as a consequence, changes in pelvic orientations were not significant (Chaffin et al., 2006). Hence, the error in knee angle estimation was considered as negligible in the present context. The AD and AI (Assaiante and Amblard, 1993; Amblard et al., 2001) were used to quantify the stabilization of a given body segment with respect to both the global coordinate system and the inferior body segment. The $\mathrm{AD}$ for each body segment was defined as the $\mathrm{SD}$ of the angular distribution with respect to the global coordinate system. The AI was defined as follows:

$$
\text { Anchoring index }(A I)=\frac{\left(\sigma_{r}-\sigma_{a}\right)}{\left(\sigma_{r}+\sigma_{a}\right)}
$$

where $\sigma_{a}$ is the $\mathrm{AD}$ of a given body segment and $\sigma_{r}$ is the SD of the relative angular distribution of the body segment being considered with respect to the axes associated with the inferior body segment (Assaiante and Amblard, 1993; Amblard et al., 2001). For example, a negative head AI indicates a more predominant head stabilization on the neck than in space, whereas a positive head AI indicates a more predominant head stabilization in space than on the neck (Amblard et al., 2001).

The four metrics used to characterize changes in the COP displacements were ellipse area, shift vector magnitude and direction, and rootmean-square (RMS) sway. First, 95\% confidence interval ellipses were fit to the 2D COP trajectories for each period. Next, the major and minor axes and center points of each ellipse were used to compute the areas of the COP trajectories. In addition, the center of each ellipse was used to calculate the $2 \mathrm{D}$ shift vector that quantified the magnitude and direction (e.g., azimuth angle) of the COP displacement. A preshift vector was computed from the origin (defined as the participant's initial position on the force plate at the beginning of the trial) to the center of the previbration ellipse. Similarly, the per- and post-shift vectors were computed using the centers of the pre- and per-vibration ellipses and the centers of per- and post-vibration ellipses, respectively. Finally, RMS values of AP and ML COP displacements were computed for each period.

All metrics were normally distributed for each body segment (Levene's test of equality of error variances). Hence, an ANOVA was used to test the main and interaction effects. Because trial repetition was not significant, the two repetitions of each trial were averaged for each participant for all metrics. A three-way ANOVA was conducted to determine the main effects of stance (normal and Romberg), covibration (four covibration conditions and the ALL condition), and period (pre-, per-, and postvibration periods) as well as their interactions for each analysis metric (i.e., maximum displacements, maximum joint angles, mean ADs). However, the AI analysis was considered only for the per-vibration period. Post hoc analysis for each dependent variable (i.e., metric) was performed using Sidak's method to determine which factors influenced the main and interaction effects. The level of significance was chosen to be $p<0.05$.

\section{Results}

\section{Displacements and joint angles}

Figure 2 shows the averaged values of maximum displacements for each body landmark across all participants in the AP direction as a function of the pre- and per-vibration periods for each covibration condition during normal stance. The displacement of the head, neck, lower torso, and knee resulting from the covibration corresponded to $2.11,0.47,-3.2$, and $-1.45 \mathrm{~cm}$ for the B IO covibration (Fig. $2 A$ ), and $-1.3,-0.21,3.3$, and $1.68 \mathrm{~cm}$ for the $\mathrm{B}$ ES covibration (Fig. $2 B$ ), respectively.

The ANOVA indicated that the main effects of covibration and period as well as the covibration $X$ period interaction were significant for the displacement and joint angle in the AP direction (Table 1). However, no significant changes in the displacement and joint angle were observed in the ML direction for stance, period, and their interactions in any covibration condition. Post hoc analysis showed that displacement magnitudes and joint angles were significantly greater during the per- than the pre-vibration period (displacement, $p<0.005$; angle, $p<0.001$ ) only for the B IO and B ES covibrations in both stance conditions. These changes were negligible for the L IO-ES (displacement, $p>$ 0.32 ; angle, $p>0.30$ ), the R IO-ES (displacement, $p>0.60$; angle, $p>0.63$ ), and the ALL (displacement, $p>0.11$; angle, $p>0.43$ ) conditions, regardless of the stance.

Figure $3 B$ shows the average of the maximum values of each joint angle (as defined in Fig. $3 A$ ) in the AP direction during the pre- and per-vibration periods for the B IO and B ES covibration 
Table 1. Statistically significant results of the dependent variables (i.e., location $[\mathrm{L}]$ and period $[\mathrm{P}]$ ) and their interactions for the displacement and angle of individual body segments in the AP direction

\begin{tabular}{lllllc}
\hline Dependent variable & Body joint & Effects & df & $F$ & $\operatorname{Pr}>F$ \\
\hline Displacement & Head & $\mathrm{L}$ & 4,270 & 18.64 & $<0.0001$ \\
& & $\mathrm{P}$ & 2,270 & 44.94 & $<0.0001$ \\
& & $\mathrm{~L} \times \mathrm{P}$ & 8,270 & 4.76 & $<0.0001$ \\
& & $\mathrm{~L}$ & 4,270 & 2.38 & 0.048 \\
& & $\mathrm{P}$ & 2,270 & 18.67 & $<0.0001$ \\
& & $\mathrm{~L} \times \mathrm{P}$ & 8,270 & 2.15 & 0.034 \\
& & $\mathrm{~L}$ & 4,270 & 483.63 & $<0.0001$ \\
& & $\mathrm{P}$ & 2,270 & 495.66 & $<0.0001$ \\
& Knee & $\mathrm{L} \times \mathrm{P}$ & 8,270 & 132.86 & $<0.0001$ \\
& & $\mathrm{~L}$ & 4,270 & 395.36 & $<0.0001$ \\
& $\mathrm{P}$ & 2,270 & 451.68 & $<0.0001$ \\
& Neck & $\mathrm{L} \times \mathrm{P}$ & 8,270 & 117.29 & $<0.0001$ \\
& & $\mathrm{~L}$ & 4,270 & 162.79 & $<0.0001$ \\
& $\mathrm{P}$ & 2,270 & 190.48 & $<0.0001$ \\
& Torso & $\mathrm{L} \times \mathrm{P}$ & 8,270 & 45.80 & $<0.0001$ \\
& & $\mathrm{~L}$ & 4,270 & 756.79 & $<0.0001$ \\
& $\mathrm{P}$ & 2,270 & 688.09 & $<0.0001$ \\
& Knee & $\mathrm{L} \times \mathrm{P}$ & 8,270 & 210.87 & $<0.0001$ \\
& & $\mathrm{~L}$ & 4,270 & 255.91 & $<0.0001$ \\
& $\mathrm{P}$ & 2,270 & 279.35 & $<0.0001$ \\
& Ankle & $\mathrm{L} \times \mathrm{P}$ & 8,270 & 65.25 & $<0.0001$ \\
& & $\mathrm{~L}$ & 4,270 & 432.74 & $<0.0001$ \\
& $\mathrm{P}$ & 2,270 & 473.45 & $<0.0001$ \\
& $\mathrm{~L} \times \mathrm{P}$ & 8,270 & 127.85 & $<0.0001$ \\
& & & & &
\end{tabular}

Pr, Probability.

conditions across all participants during normal stance. Post hoc analysis showed that angle changes were larger for the neck and torso compared with both knee and ankle when covibration was applied to the skin over either the IO or ES muscles regardless of stance. In addition, for the B IO and B ES covibrations, angle changes were significantly larger for the torso than the neck. However, the pairwise comparisons between the knee and ankle angles were not significant.

The average latency of vibration-induced changes in joint angles was $\sim 800 \mathrm{~ms}$ after the onset of vibration. The latency was calculated using a 10-sample moving average (i.e., $0.1 \mathrm{~s}$ interval) and a threshold ( $|0.3|$ degree threshold) for each trial (Lee et al., 2012c). This latency was similar (not statistically different, $p>$ 0.05 ) between the covibration conditions producing postural effects (i.e., B IO and B ES) regardless of stance.

\section{Angular dispersion}

Table 2 summarizes the results of the AD for each body segment in the AP direction across all participants during the pervibration period for the $\mathrm{B}$ IO and B ES covibration conditions during normal stance. The statistical analysis indicated that the main effects of covibration and period as well as the covibration $\times$ period interaction were significant for the $\mathrm{AD}$ in the $\mathrm{AP}$ direction, as shown in Table 3. However, no significant changes in the $\mathrm{AD}$ for any body segment were observed in the ML direction for stance, period, and their interactions in all covibration conditions. Post hoc analysis showed a significantly greater AD $(p<0.0001)$ for all body segments during the per- than the pre-vibration period when covibration was applied to the skin over the IO or ES muscle locations in both stance conditions. For these covibration conditions (i.e., B IO and B ES), the AD of the head and torso was significantly greater than that of the upper leg and lower leg regardless of stance. The pairwise comparisons for
ADs between the head and torso and the upper leg and lower leg were not significant. However, changes in the AD were not significant for any body segment in the L IO-ES $(p>0.42)$, the $\mathrm{R}$ IO-ES $(p>0.27)$, or the ALL $(p>0.13)$ conditions regardless of stance.

\section{Anchoring index}

Figure 4 shows the mean AI for all body segments in the AP direction during the per-vibration period for the B IO and B ES covibration conditions across all participants during normal stance. Negative values of the head and upper leg AI index indicate a predominant head stabilization relative to the neck and indicated a predominant leg stabilization (because knee and ankle angles are similar) relative to the ankle than stabilizations relative to the absolute vertical direction. On the other hand, positive values of the torso AI indicated a predominant torso stabilization relative to the absolute vertical direction than relative to L5/S1. The results of the statistical analysis in Table 3 show that the main effects of covibration were significant for the AI in the AP direction. However, post hoc analysis showed that these changes were significant for the head $(-)$, torso $(+)$, and upper leg $(-)$ in only two vibration conditions (B IO and B ES) for both stances. AIs were not significant in the ML direction in any of the vibration conditions for either stance.

\section{COP}

No COP metrics were significantly affected by any covibration condition for either stance (ellipse area, $p>0.07$; shift vector magnitude, $p>0.17$; shift vector direction, $p>0.59$; AP RMS, $p>0.06$; and ML RMS, $p>0.54)$. Although not significant, there was a slight increase in the AP sway magnitude during vibration.

\section{Discussion}

This study shows the reorganization of posture in a coordinated fashion when cutaneous information from the torso is modified/ manipulated. This reorganization appears to result from a torsoleg synergy driven by an internal constraint aiming at regulating the COP because its position did not change significantly when body segments moved in response to vibrotactile stimulation. Furthermore, the results confirm the contribution of cutaneous information to upper body spatial representation and support a summation property for that information.

\section{Coordinated reorganization of posture}

This study reveals that body segments (i.e., head, torso, upper leg, and lower leg) contribute conjointly/cooperatively to postural organization and the preservation of postural equilibrium when torso cutaneous information is manipulated. B IO and B ES covibrations induced opposite displacements of the upper and lower body segments. These effects were independent of the stance condition. Similar to local responses to neck muscle vibration (Verrel et al., 2011), our findings show that vibrationinduced cutaneous activity of anterior and posterior torso areas at the level of the main joint produce multisegmental postural responses in the sagittal plane. This type of response is consistent with our previous observations corresponding to single tactile vibration (Lee et al., 2012b). In addition, the equal latency of body segment rotations about the joints indicates a synchrony. Although these postural reconfigurations are unperceived involuntary responses (Lee et al., 2012b), as is the case when muscle proprioceptive or foot sole information is biased by vibration (Goodwin et al., 1972; Kavounoudias et al., 2001), the synchronization of body segment displacements is similar to 
those observed in voluntary anteriorposterior head-trunk displacements in the sagittal plane (Crenna et al., 1987). Hence, this "synergy," initially qualified by Babinski (1899), seems to reflect a learned/adapted type of postural control generically used by the CNS to maintain balance in response to either changes in torso sensory information or torso voluntary axial movements. It is worth noting that virtual (from manipulation of sensory information by vibration) and real displacements of the torso are interpreted in the same way by the CNS because both correspond to real sensory information. Thus, similar interpretations (torso movements) result in similar responses regardless of the movement speed (i.e., our responses were slow, whereas voluntary anterior-posterior movements were either slow or fast). In either case, the simultaneous displacement of body segments indicates a feedforward mode of control (Crenna et al., 1987), which is commonly used in compensatory responses (Bouisset and Zattara, 1981; Do et al., 1991). We suggest that the feedforward mode of control (and associated synergy) may account for the negligible displacement of the COP observed here. Overall, these results lead us to suggest that, in the context of torso perturbation, posture is reorganized in a coordinated fashion to control/minimize the displacement of the COP. This is in agreement with the hypothesis proposing that postural equilibrium involves the coordination of multiple joints to stabilize the body's center of mass (Crenna et al., 1987; Kuo and Zajac, 1993; Kuo, 1995). Notably, the small angular displacements of the neck in opposition to the angular displacements of the torso (Fig. 3) and the negative values of the head-neck anchoring index (Fig. 4) confirm a tendency to stabilize the head relative to the neck. In other words, a multijoint strategy is adopted to preserve balance. The small magnitude of head displacements may be interpreted as an interaction between mechanical (Kim et al., 2000) and vestibular contributions to balance. From a mechanical perspective, head displacement has been shown to contribute to the control of the center of gravity location (Kim et al., 2000; Kim, 2005). From a neurophysiological perspective, the vestibular system is used to stabilize head position in space (Della Santina et al., 2005; Angelaki and Cullen, 2008). In the present case, the interaction between these two mechanisms may reduce head displacement and favor stronger head stabilization relative to the neck than space. Finally, a multisegmental postural response may not be the outcome in different contexts. For example, vibration applied to the Achilles tendon (Hayashi et al., 1981; Kavounoudias et al., 2001; Aimonetti et al., 2007) or to the plantar sole (Kavounoudias et al., 1999) induces whole-body shifts as indicated by significant displacements of the center of gravity. Hence, differences in COP displacements resulting from upper body or ankle-foot vibration indicate that postural control strategies may be highly dependent on the part of the body (upper vs lower) providing conflicting sensory information and the associated compensatory strategies. This assumption is further supported by whole-body inclinations associated with ankle vibration (Abrahamova et al., 2009; Thompson et al., 2011). Nevertheless, whole-body inclination is not restricted to ankle rotation as indicated by changes in knee

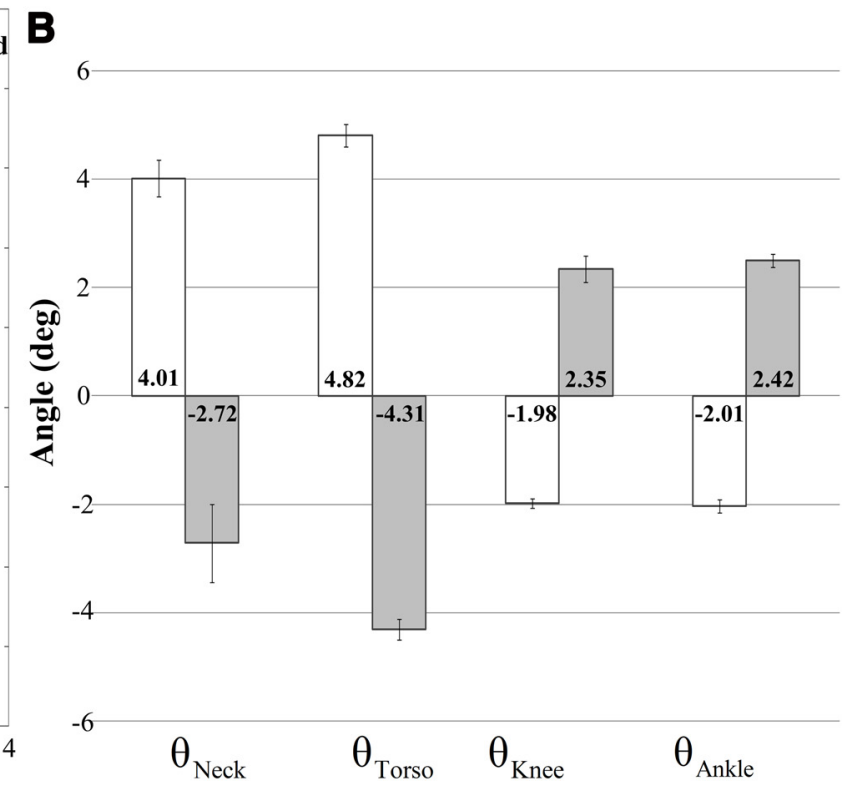

Figure 3. $A$, Computation of each joint angle in the AP direction. Each circle indicates the marker location at the head, $C 7, \mathrm{~L} 5 / \mathrm{S} 1$ knee, and ankle. Subplot indicates the scale and direction of angles. $\boldsymbol{B}$, Average maximum AP joint angles across all participant during normal stance. White and gray bars correspond to the B 10 and BES covibration conditions, respectively. Error bars indicate $\mathrm{SE}$, and numbers inside the bars indicate the corresponding average.

Table 2. The AD for each body segment

\begin{tabular}{lll}
\hline Covibration condition & Body segment & $\mathrm{AD}\left({ }^{\circ}\right)$, mean $\pm \mathrm{SE}$ \\
\hline B I0 & Head & $2.68 \pm 0.18$ \\
& Torso & $2.88 \pm 0.11$ \\
& Upper leg & $1.57 \pm 0.15$ \\
& Lower leg & $1.48 \pm 0.09$ \\
B ES & Head & $2.26 \pm 0.32$ \\
& Torso & $2.72 \pm 0.19$ \\
& Upper leg & $1.38 \pm 0.11$ \\
& Lower leg & $1.47 \pm 0.12$ \\
\hline
\end{tabular}

Table 3. Statistically significant results of the dependent variables (i.e., location $[\mathrm{L}]$ and period $[\mathrm{P}]$ ) and their interactions for the $A D$ and $A I$ in the AP direction

\begin{tabular}{|c|c|c|c|c|c|}
\hline Dependent variable & Body segment & Effects & df & $F$ & $\operatorname{Pr}>F$ \\
\hline \multirow[t]{12}{*}{$A D$} & \multirow[t]{3}{*}{ Head } & $L$ & 4,270 & 141.03 & $<0.0001$ \\
\hline & & $P$ & 2,270 & 221.50 & $<0.0001$ \\
\hline & & $L \times P$ & 8,270 & 47.34 & $<0.0001$ \\
\hline & \multirow[t]{3}{*}{ Torso } & $\mathrm{L}$ & 4,270 & 646.21 & $<0.0001$ \\
\hline & & $P$ & 2,270 & 797.97 & $<0.0001$ \\
\hline & & $L \times P$ & 8,270 & 221.58 & $<0.0001$ \\
\hline & \multirow[t]{3}{*}{ Upper leg } & $\mathrm{L}$ & 4,270 & 223.98 & $<0.0001$ \\
\hline & & $P$ & 2,270 & 327.05 & $<0.0001$ \\
\hline & & $L \times P$ & 8,270 & 74.92 & $<0.0001$ \\
\hline & \multirow[t]{3}{*}{ Lower leg } & $\mathrm{L}$ & 4,270 & 337.44 & $<0.0001$ \\
\hline & & $P$ & 2,270 & 502.47 & $<0.0001$ \\
\hline & & $L \times P$ & 8,270 & 119.57 & $<0.0001$ \\
\hline \multirow[t]{4}{*}{ Al } & Head & $\mathrm{L}$ & 4,90 & 27.14 & $<0.0001$ \\
\hline & Torso & $\mathrm{L}$ & 4,90 & 15.81 & $<0.0001$ \\
\hline & Upper leg & $\mathrm{L}$ & 4,90 & 40.86 & $<0.0001$ \\
\hline & Lower leg & $L$ & 4,90 & 18.10 & $<0.0001$ \\
\hline
\end{tabular}

Pr, Probability.

and hip angles during Achilles tendon vibration (Thompson et al., 2007, 2011). Overall, our results show a transition from an ankle strategy (i.e., in-phase) during quiet stance to a multisegmental strategy (i.e., antiphase) during torso skin vibration. 


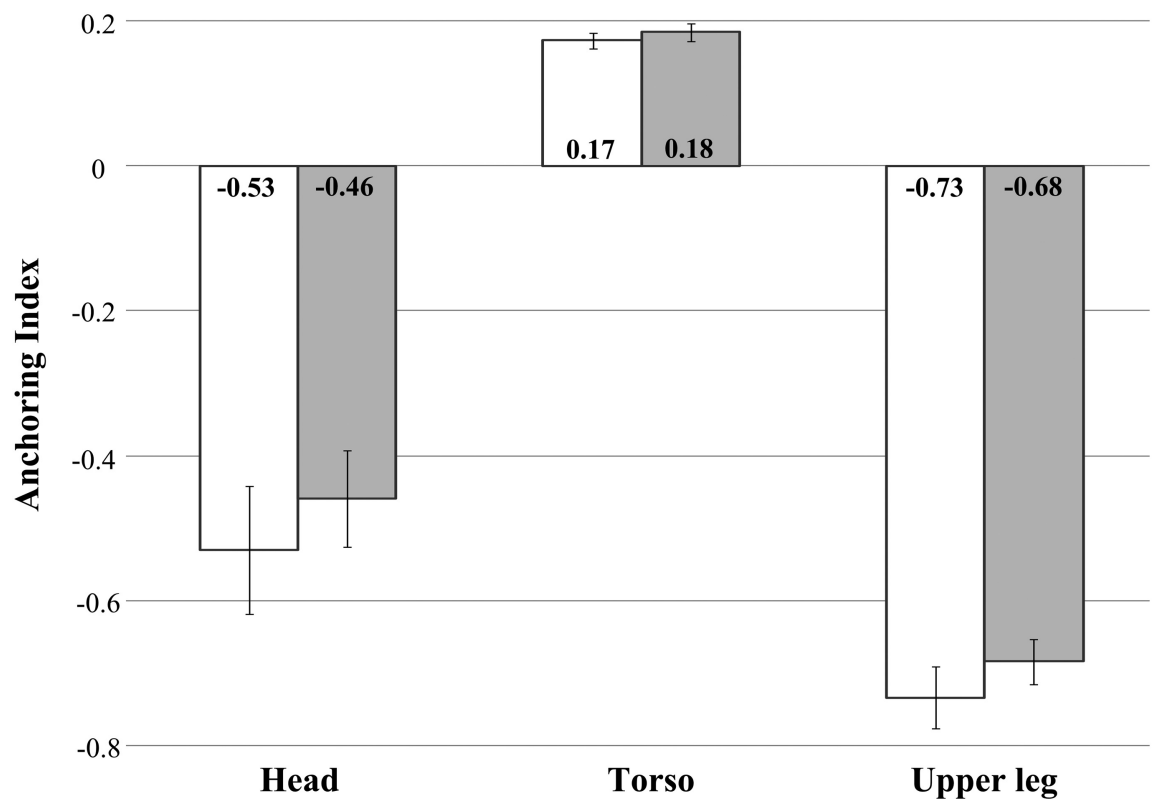

Figure 4. Average AP anchoring index for body segments (head, torso, and upper leg) across all participants as a function of the covibration location during normal stance. White and gray bars correspond to the B IO and B ES covibration conditions, respectively. Error bars indicate $S E$, and the numbers inside the bars indicate the corresponding average values.

\section{Summation effects associated with covibration}

The postural responses to B IO and B ES covibration conditions are pointed in the anterior and posterior directions, respectively, in the midsagittal plane. These directions correspond to the summations of the respective directional shifts induced by homonymous single vibration observed in our previous work, which showed that vibration applied over the skin of the left or right internal oblique or erector spinae muscle locations induced postural shifts (corresponding primarily to torso inclinations) in the direction of the vibration location (Lee et al., 2012a, b). For example, the postural shift was directed in the anterior right direction when vibration was applied to the skin over the right IO muscle locations. A symmetric effect relative to the midsagittal plane was produced when vibration was applied to the skin over the left IO muscle locations. In the covibration case, therefore, the postural shift may be interpreted as the resultant of individual effects. No significant postural changes were observed in the heteronymous covibration conditions (L IO-ES, R IO-ES), or the ALL condition regardless of stance. This absence of postural changes confirms the directional summation effect because corresponding individual/single vibrations effects were symmetrical relative to the frontal plane (Lee et al., 2012a, b). In addition, it may be assumed that the IO-ES covibration conditions are equivalent to the corresponding EO single stimulation conditions, which also do not induce postural changes (Lee et al., 2012b). Indeed, either condition (covibration, single) further emphasizes the summation phenomenon because the integrated proprioceptive information is likely to have the same meaning: stretch of the skin associated with a lateral "extension." As indicated before, a sensory message conveying information about a small skin stretch may not trigger a postural adjustment in the coronal plane because the bipedal system is more stable in the ML than AP directions (Lee et al., 2012b). Furthermore, summation effects resulting from cutaneous vibration are similar to those produced by muscle tendon covibration on behavioral (Kavounoudias et al., 2001; Romaiguère et al., 2003) and neurophysiological (Martin et al., 1986) responses. However, despite the indirect evidence of summations at the spinal level, via reflex responses (Martin et al., 1986), the integration/summation of afferent information resulting in the summation of behavioral effects is likely to take place at the central level. This assumption is supported by studies showing little or no activation of motor and premotor areas in the absence of movement illusion resulting from the covibration of antagonistic muscle pairs (Romaiguère et al., 2003). Overall, the directional summation effects confirm our proposition concerning the contribution of torso $\mathrm{cu}$ taneous information (at the tested level) to proprioception and upper body representation in space (Lee et al., 2012b). In addition, the directional coding reflects the properties of cutaneous afferents encoding the orientation of human ankle movements (Aimonetti et al., 2007). Finally, the long latency $(\sim 800 \mathrm{~ms})$ and slow drift of the observed postural shifts, already observed for corresponding single vibrations (Lee et al., 2012b), confirm the exclusion of reflex contributions and support further integrated adaptive postural responses.

\section{Sensory augmentation device applications}

Our present and previous (Lee et al., 2012b) results may have implications for the design and use of torso-based vibrotactile sensory augmentation devices for balance-related applications. Such devices provide cues for directional correction of body motion with vibrating actuators placed on the torso. These cutaneous "alarm" signals triggered at predefined thresholds and historically accompanied with the instruction to "Move away from the vibration" (repulsive cuing) have been shown to significantly reduce body sway in various populations during quiet and perturbed stances (Wall and Kentala, 2005; Sienko et al., 2008, 2010; 2012; Bechly et al., 2012; Haggerty et al., 2012; Lee et al., 2012c). Although repulsive cuing strategies have been regularly used for such applications, they may not be congruent with kinesthetic information from the stimulated cutaneous receptors. Attractive cues (with the instruction to "Move toward the vibration"), which offer stimulus-response compatibility, may improve the use of these devices. In addition, multiple or covibrotactile stimulations may be more effective because they generate a stronger afferent flow and thus provide more versatile directional information for more accurate balance corrections.

In conclusion, our findings indicate that postural reorganization in response to vibration-induced changes in torso cutaneous proprioceptive information corresponds to a multisegmental synergy. In addition, stimuli combinations applied over torso prime mover muscles result in a directional summation of body responses obtained from individual stimulations. This summation confirms a proprioceptive role of torso cutaneous information issued from receptors in the skin over the torso prime mover muscles. To our knowledge, our results are the first to show the proprioceptive properties of torso skin receptor information. They also suggest that the axial multisegmental synergy may be a generic response to preservation of COP stability in cases involving torso perturbations/movements. 


\section{References}

Abrahámová D, Mancini M, Hlavacka F, Chiari L (2009) The age-related changes of trunk responses to Achilles tendon vibration. Neurosci Lett 467:220-224. CrossRef Medline

Aimonetti JM, Hospod V, Roll JP, Ribot-Ciscar E (2007) Cutaneous afferents provide a neuronal population vector that encodes the orientation of human ankle movements. J Physiol 580:649-658. CrossRef Medline

Amblard B, Assaiante C, Vaugoyeau M, Baroni G, Ferrigno G, Pedotti A (2001) Voluntary head stabilisation in space during oscillatory trunk movements in the frontal plane performed before, during and after a prolonged period of weightlessness. Exp Brain Res 137:170-179. CrossRef Medline

Anderson DJ, Reschke MF, Homick JE, Werness SA (1986) Dynamic posture analysis of Spacelab-1 crew members. Exp Brain Res 64:380-391. CrossRef Medline

Angelaki DE, Cullen KE (2008) Vestibular system: the many facets of a multimodal sense. Annu Rev Neurosci 31:125-150. CrossRef Medline

Assaiante C, Amblard B (1993) Ontogenesis of head stabilization in space during locomotion in children: influence of visual cues. Exp Brain Res 93:499-515. CrossRef Medline

Babinski J (1899) De l'asynergie cérébelleuse. Rev Neurol 7:806-816.

Bechly KE, Carender WJ, Myles JD, Sienko KH (2013) Determining the preferred modality for real-time biofeedback during balance training. Gait Posture 37:391-396. CrossRef Medline

Bouisset S, Zattara M (1981) A sequence of postural movements precedes voluntary movement. Neurosci Lett 22:263-270. CrossRef

Burke D, Hagbarth KE, Löfstedt L, Wallin BG (1976a) The responses of human muscle spindle endings to vibration during isometric contraction. J Physiol 261:695-711. Medline

Burke D, Hagbarth KE, Löfstedt L, Wallin BG (1976b) The response of human muscle spindle endings to vibration of non-contracting muscles. J Physiol 261:673-693. Medline

Chaffin DB, Andersson GB, Martin BJ (2006) Occupational biomechanics. New York: Wiley-Interscience.

Collins DF, Refshauge KM, Todd G, Gandevia SC (2005) Cutaneous receptors contribute to kinesthesia at the index finger, elbow, and knee. J Neurophysiol 94:1699-1706. CrossRef Medline

Creath R, Kiemel T, Horak F, Peterka R, Jeka J (2005) A unified view of quiet and perturbed stance: simultaneous coexisting excitable modes. Neurosci Lett 377:75-80. CrossRef Medline

Crenna P, Frigo C, Massion J, Pedotti A (1987) Forward and backward axial synergies in man. Exp Brain Res 65:538-548. CrossRef Medline

Della Santina CC, Potyagaylo V, Migliaccio AA, Minor LB, Carey JP (2005) Orientation of human semicircular canals measured by three-dimensional multiplanar CT reconstruction. J Assoc Res Otolaryngol 6:191-206. CrossRef Medline

Do MC, Nouillot P, Bouisset S (1991) Is balance or posture at the end of a voluntary movement programmed? Neurosci Lett 130:9-11. CrossRef Medline

Edin B (2001) Cutaneous afferents provide information about knee joint movements in humans. J Physiol 531:289-297. CrossRef Medline

Fallon JB, Macefield VG (2007) Vibration sensitivity of human muscle spindles and Golgi tendon organs. Muscle Nerve 36:21-29. CrossRef Medline

Gatev P, Thomas S, Kepple T, Hallett M (1999) Feedforward ankle strategy of balance during quiet stance in adults. J Physiol 514:915-928. CrossRef Medline

Goodwin GM, McCloskey DI, Matthews PB (1972) The contribution of muscle afferents to kinaesthesia shown by vibration induced illusions of movement and by the effects of paralysing joint afferents. Brain 95:705-748. CrossRef Medline

Haas G, Diener HC, Rapp H, Dichgans J (1989) Development of feedback and feedforward control of upright stance. Dev Med Child Neurol 31:481-488. Medline

Haggerty S, Jiang LT, Galecki A, Sienko KH (2012) Effects of biofeedback on secondary-task response time and postural stability in older adults. Gait Posture 35:523-528. CrossRef Medline

Hayashi R, Miyake A, Jijiwa H, Watanabe S (1981) Postural readjustment to body sway induced by vibration in man. Exp Brain Res 43:217-225. CrossRef Medline

Honegger F, van Spijker GJ, Allum JH (2012) Coordination of the head with respect to the trunk and pelvis in the roll and pitch planes during quiet stance. Neuroscience 213:62-71. CrossRef Medline
Horak FB, Kuo AD (2000) Postural adaptation for altered environments, tasks, and intentions (Winters J, Crago P, eds). New York: Springer.

Ivanenko YP, Talis VL, Kazennikov OV (1999) Support stability influences postural responses to muscle vibration in humans. Eur J Neurosci 11:647-654. CrossRef Medline

Johansson RS, Landström U, Lundström R (1982) Sensitivity to edges of mechanoreceptive afferent units innervating the glabrous skin of the human hand. Brain Res 244:27-35. CrossRef Medline

Kavounoudias A, Gilhodes JC, Roll R, Roll JP (1999) From balance regulation to body orientation: two goals for muscle proprioceptive information processing? Exp Brain Res 124:80-88. CrossRef Medline

Kavounoudias A, Roll R, Roll JP (2001) Foot sole and ankle muscle inputs contribute jointly to human erect posture regulation. J Physiol 532:869-878. CrossRef Medline

Kiemel T, Elahi AJ, Jeka JJ (2008) Identification of the plant for upright stance in humans: multiple movement patterns from a single neural strategy. J Neurophysiol 100:3394-3406. CrossRef Medline

Kim K (2005) Head movement control in visually guided tasks: postural goal and optimality. Ann Arbor, MI: University of Michigan.

Kim K, Martin BJ, Park W (2000) Head orientation in visually guided tasks. Warrendale, PA: Society of Automotive Engineers.

Knibestöl M, Vallbo AB (1970) Single unit analysis of mechanoreceptor activity from the human glabrous skin. Acta Physiol Scand 80:178-195. CrossRef Medline

Kuo AD (1995) An optimal control model for analyzing human postural balance. IEEE Trans Biomed Eng 42:87-101. CrossRef Medline

Kuo AD, Zajac FE (1993) Human standing posture: multi-joint movement strategies based on biomechanical constraints. Prog Brain Res 97:349-358. CrossRef Medline

Lee BC, Martin BJ, Sienko KH (2012a) Comparison of non-volitional postural responses induced by two types of torso based vibrotactile stimulations. In: IEEE Haptics Symposium (HAPTICS), pp 195-198. Vancouver.

Lee BC, Martin BJ, Sienko KH (2012b) Directional postural responses induced by vibrotactile stimulations applied to the torso. Exp Brain Res 222:471-482. CrossRef Medline

Lee BC, Kim J, Chen S, Sienko KH (2012c) Cell phone based balance trainer. J Neuroeng Rehabil 9:10. CrossRef Medline

Lundström R (1984) Local vibrations: mechanical impedance of the human hand's glabrous skin. J Biomech 17:137-144. CrossRef Medline

Martin B, Gauthier GM, Roll JP, Hugon M, Harlay F (1980) Effects of whole-body vibrations on standing posture in man. Aviat Space Environ Med 51:778-787. Medline

Martin BJ, Roll JP, Gauthier GM (1986) Inhibitory effects of combined agonist and antagonist muscle vibration on H-reflex in man. Aviat Space Environ Med 57:681-687. Medline

Massion J (1992) Movement, posture and equilibrium: interaction and coordination. Prog Neurobiol 38:35-56. CrossRef Medline

Ribot-Ciscar E, Vedel JP, Roll JP (1989) Vibration sensitivity of slowly and rapidly adapting cutaneous mechanoreceptors in the human foot and leg. Neurosci Lett 104:130-135. CrossRef Medline

Roll JP, Vedel JP, Ribot E (1989) Alteration of proprioceptive messages induced by tendon vibration in man: a microneurographic study. Exp Brain Res 76:123-222. CrossRef Medline

Roll R, Gilhodes JC, Roll JP, Popov K, Charade O, Gurfinkel V (1998) Proprioceptive information processing in weightlessness. Exp Brain Res 122:393-402. CrossRef Medline

Romaiguère P, Anton JL, Roth M, Casini L, Roll JP (2003) Motor and parietal cortical areas both underlie kinaesthesia. Brain Res Cogn Brain Res 16:74-82. CrossRef Medline

Sienko KH, Balkwill MD, Oddsson LI, Wall C (2008) Effects of multidirectional vibrotactile feedback on vestibular-deficient postural performance during continuous multi-directional support surface perturbations. J Vestib Res 18:273-285. Medline

Sienko KH, Vichare VV, Balkwill MD, Wall C 3rd (2010) Assessment of vibrotactile feedback on postural stability during pseudorandom multidirectional platform motion. IEEE Trans Biomed Eng 57:944-952. CrossRef Medline

Sienko KH, Balkwill MD, Wall C 3rd (2012) Biofeedback improves postural control recovery from multi-axis discrete perturbations. J Neuroeng Rehabil 9:53. CrossRef Medline

Thompson C, Bélanger M, Fung J (2007) Effects of bilateral Achilles tendon 
vibration on postural orientation and balance during standing. Clin Neurophysiol 118:2456-2467. CrossRef Medline

Thompson C, Bélanger M, Fung J (2011) Effects of plantar cutaneomuscular and tendon vibration on posture and balance during quiet and perturbed stance. Hum Mov Sci 30:153-171. CrossRef Medline

Vedel JP, Roll JP (1982) Response to pressure and vibration of slowly adapting cutaneous mechanoreceptors in the human foot. Neurosci Lett 34:289-294. CrossRef Medline
Verrel J, Cuisinier R, Lindenberger U, Vuillerme N (2011) Local and global effects of neck muscle vibration during stabilization of upright standing. Exp Brain Res 210:313-324. CrossRef Medline

Wall C 3rd, Kentala E (2005) Control of sway using vibrotactile feedback of body tilt in patients with moderate and severe postural control deficits. J Vestib Res 15:313-325. Medline

Winter DA (1995) A.B.C. (Anatomy, Biomechanics, and Control) of balance during standing and walking. Waterloo, Ontario: University of Waterloo. 